\title{
The Covert Orienting of Visual Attention Following Severe Traumatic Brain Injury*
}

\author{
Andrew J. Bate ${ }^{1}$, Jane L. Mathias ${ }^{2}$, and John R. Crawford ${ }^{3}$ \\ ${ }^{1}$ Julia Farr Services, Community Rehabilitation Program, Adelaide, South Australia, \\ ${ }^{2}$ The University of Adelaide, Department of Psychology, Adelaide, South Australia, and \\ ${ }^{3}$ The University of Aberdeen, King's College, Department of Psychology, Aberdeen, Scotland
}

\begin{abstract}
Attentional problems have frequently been identified following traumatic brain injuries (TBIs) using both clinical assessments and self-report measures. Unfortunately, most measures of attention do not enable us to determine the underlying basis of these attentional deficits. One exception is Posner's Covert Orienting of Attention Task (COAT), which is designed to identify some of the fundamental mental operations underlying attention. This study sought to determine whether the COAT task could identify discrete attentional deficits following TBI beyond those caused by reduced speed of information processing. Thirty five patients who had sustained a severe TBI were compared to 35 age-matched controls. Results revealed that, although the reaction times of the patients with TBI were significantly slower than the controls, there were no differences between the two groups in terms of their ability to disengage, move, and engage their attention. The introduction of a secondary (language) task produced no significant difference between the two groups on the COAT task. However, there was a significant difference between the two groups on the language-based task, suggesting a deficit in auditory-verbal attention under dual task conditions.
\end{abstract}

Difficulties with concentration and attention are amongst the most common problems reported by people following non-penetrating traumatic brain injuries (TBIs) (Gronwall, 1987; McKinlay, Brooks, Bond, Martinage, \& Marshall, 1981; van Zomeren \& Brouwer, 1987). In fact, a significant proportion of patients with severe TBI still report such difficulties more than two years post-injury (Ponsford, Olver, \& Curran, 1995). These attentional deficits compromise virtually all other cognitive processes including memory, learning, and reasoning abilities (Schmitter-Edgecombe, 1996) and, as a result, provide a major obstacle to rehabilitation and to the patient's successful reintegration into the community. In everyday life, these difficulties present themselves as increased distractibility (McKinlay et al., 1981; Schmitter-Edgecombe \& Kibby,
1998) and a tendency to become overloaded when having to deal with more than one thought at a time (Lezak, 1995).

While a number of studies have reported deficits in focused (Godefroy, Lhullier, \& Rousseaux, 1996; van Zomeren, 1981), divided (Hartman, Pickering, \& Wilson, 1992; Stuss, Stetham, Hugenholtz, \& Richard, 1989) and sustained attention (Loken, Thornton, Otto, \& Long, 1995; Stuss, Pogue, Buckle, \& Bondar, 1994; Whyte, Polansky, Fleming, Coslett, \& Cavullucci, 1995) following severe TBI, there is some debate about whether these problems reflect genuine deficits in attention. For example, Ponsford and Kinsella (1992), as well as van Zomeren and Brouwer (1987), argue that the poorer performance of patients with TBI can be explained in terms of a reduced speed of information processing. How-

\footnotetext{
* This research was supported by a grant from the Julia Farr Foundation (Inc.). The authors would like to thank all of the participants who took part in the study. This study formed part of a doctoral dissertation being completed by the first author.

Address correspondence to: Andrew Bate, Julia Farr Services, Community Rehabilitation Program, 8 Briar Road, Felixstow, South Australia, 5070. Tel.: +61 88337 3000. Fax: +61 88365 2652. E-mail: abate@vtown.com.au Accepted for publication: June 22, 2000.
} 
ever, studies examining the orienting of visual attention using Posner's Covert Orienting of Attention Task (COAT; Posner, 1980; Posner, Cohen, \& Rafal, 1982, Posner, Walker, Friedrich, \& Rafal, 1984; Posner, Inhoff, Friedrich, \& Cohen, 1987) have detected specific attentional deficits in TBI (Cremona-Meteyard, Clark, Wright, \& Geffen, 1992; Cremona-Meteyard \& Geffen, 1994).

The COAT task was specifically designed to measure some of the fundamental operations underlying the orienting of visual attention (i.e., disengage, move, and engage). It involves a simple detection and reaction time (RT) task that examines the effects of valid, invalid, and neutral spatial cues upon RT (Posner, 1980; Posner, et al., 1982, 1984, 1987). These cues are presented at a central fixation point and consist of either an arrow pointing in the direction of the imminent target or in the opposite direction (invalid cue). Neutral cues take the form of a cross (+) and provide no directional information. The effect of the valid or invalid directional cues upon the orienting of visual attention is measured by comparing RTs in response to these conditions against RTs to a neutral cue. Healthy experimental participants display faster RTs to valid than neutral cues (benefit), and slower RTs to invalid than neutral cues (cost).

In addition to calculating the benefits and costs associated with valid and invalid cues, Posner et al. (1984) claim to be able to "... distinguish more finely the mental operations involved in target detection" (p. 1864). For example, if a valid cue is presented, and sufficient time is allowed for attention to orient to that location, then the only operation to be performed when the target appears at that location is for the target to be engaged. In a situation where the participant is fixated at a central point, and given no cue (or a neutral cue), when the target is presented they must first move to the target location and then engage the target. Finally, if an invalid cue is presented, then the person must disengage attention from the cued location, move to the target location and engage the target (Posner et al., 1984).

Posner and colleagues have also introduced a dual task condition, combining both the COAT and a simple phoneme detection task, in order to assess a participant's ability to divide his or her attention (Posner et al., 1987). Robertson (1995) has suggested that dual task conditions have the potential to 'unmask' attentional deficits that would otherwise go undetected. Findings from dual task studies involving the COAT (Posner et al., 1987), in addition to extensive work in the brain imaging fields (Petersen, Fox, Posner, Mintun, \& Raichle, 1988; Posner, Petersen, Fox, \& Raichle, 1988; Posner, Sandson, Dhawan, \& Shulman, 1989; Roland, 1985), have led Posner and colleagues (Posner \& Petersen, 1990) to propose a model of attention based on both anterior and posterior attention systems.

Within Posner's model of attention, it is argued that there are three major interconnected components or networks of attention, each of which can be linked to an underlying neuroanatomical system (Posner \& Petersen, 1990). These networks include a selection or executive network which is responsible for selecting relevant stimuli and inhibiting irrelevant ones, a vigilance network for maintaining readiness to respond, and an orientation network, responsible for engaging, moving, and disengaging attention in space (Posner \& Petersen, 1990). Furthermore, neuroimaging and lesion studies have identified the neuroanatomical systems that are thought to underlie these attentional networks (Posner et al., 1988). As the frontal lobes have been implicated in the activity of both the selection/executive and vigilance networks, this attentional system is known as the anterior attention system (Posner \& Raichle, 1994). In contrast, the orienting of visual attention has been shown to produce increased activity of the posterior parietal lobe (Posner et al., 1989) and has therefore been linked to the posterior attention system (Posner \& Raichle, 1994). In addition to performing selective/executive functions, the anterior system, particularly the anterior cingulate, has been found to play a central role in language functions (Posner et al., 1988). Studies of cerebral blood flow under dual task conditions have revealed that the anterior and posterior systems interact, and that the anterior cingulate plays a role in the executive control of attention (Posner et al., 1989). This interaction is demonstrated by the finding that both controls, and patients with parietal lesions, 
produce slower overall RTs and orient more slowly to cues (i.e., reduced benefit and cost) in dual task situations involving both language and visual spatial orienting (Posner \& Raichle, 1994). The additional load placed upon the anterior system, caused by the introduction of a secondary task, impacts upon its ability to carry out executive functions and, consequently, affects the posterior attention system (i.e., reducing performance on the COAT task). Thus, although the visual orienting of attention is controlled by the posterior system, visual orienting still requires access to the anterior executive network under dual task conditions in order to allocate attentional resources (Posner \& Raichle, 1994).

The COAT task has been widely used in the experimental literature and has identified specific attentional deficits in a variety of diagnostic groups, including Parkinson's Disease (Wright, Burns, Geffen, \& Geffen, 1990), Dementia of the Alzheimer's Type (Wright, Cremona-Meteyard, Geffen, \& Geffen, 1994), Attention Deficit Disorder (Swanson, Posner, Potkin, Bonforte, Youpa, Fiore, Cantwell, \& Crinella, 1991), Progressive Supranuclear Palsy (Posner et al., 1982), and patients who have suffered cerebral vascular accidents (CVAs), particularly with those who have lesions to the parietal lobes (Posner et al., 1987). Given the pathophysiology of TBI and, in particular, the frequent diagnosis of damage to the frontal lobes (Blumbergs, 1997), the Posner model would predict a greater disruption of the anterior attention system, in the presence of a preserved posterior attention system, when comparing TBI and control participants. Such a prediction would further imply intact COAT task performance in participants with TBI under single task conditions. Furthermore, the additional load placed upon the anterior (executive) attention system by the introduction of the dual task condition, while resulting in a reduction in performance on the COAT task across both groups, would result in a significantly greater decrement in the group with TBI.

To date, only a relatively small number of studies have applied the Posner paradigm to TBI (Cremona-Meteyard et al., 1992; Cremona-Meteyard \& Geffen, 1994; Pavese, Heidrich, Sohlberg, Laughlin, \& Posner, submitted for publication;
Sandson, Crosson, Posner, Barco, Velozo, \& Brobeck, 1988). To our knowledge, there have not been any studies that have examined the COAT task performance of participants with TBI under dual task conditions. An early study by Sandson et al. (1988) found that while the participants with TBI were overall approximately $100 \mathrm{~ms}$ slower than controls, the pattern of cost and benefit, in relation to a no-cue situation, was very similar to the control group. This finding has been further supported by a recent study which also found that, while the overall RTs of the group with TBI were slower, their pattern of orienting to the various cues was similar to the control group (Pavese et al., submitted for publication). Deficits in the orienting of attention in participants with severe TBI have, however, also been found. CremonaMeteyard et al. (1992), using a group of 11 individuals with TBI and nine matched controls, found that while there were no overall differences in RTs between the two groups, participants with TBI displayed a significantly reduced benefit in response to valid cues. According to CremonaMeteyard et al. (1992), this was taken to indicate an impairment in the ability to prealign attention with a cued location. Cremona-Meteyard and Geffen (1994) replicated these findings in a group of participants with mild TBI who were tested within 2 weeks of their injury. While these individuals displayed an overall improvement in RT when tested 12 months later, they continued to display an inability to gain an advantage from the valid directional cues.

Although there are divergent findings in relation to the performance of participants with TBI on the COAT, the findings of Cremona-Meteyard et al. $(1992,1994)$ would suggest that the Posner task warrants a more detailed examination with regard to its ability to identify discrete attentional deficits that cannot be explained solely in terms of reduced speed of information processing. In addition, this experimental paradigm has the potential to further partial out speed of information processing factors by manipulating the cue-target intervals. If participants with TBI are presented with increasingly longer cue-target intervals, sufficient time would be allowed for them to move their attention to the cued location. Any disproportional reduction in $\mathrm{RT}$ in response to either of 
the cue types could therefore be explained in terms of deficits in the ability to engage or disengage attention. As a result, the COAT task would appear to be a useful vehicle by which to examine discrete attentional processes in persons who have sustained a TBI.

Using a larger sample, the current study sought to determine the replicability of the CremonaMeteyard et al. (1992) finding that patients with severe TBI exhibit problems in 'prealigning' (engaging) attention, as indexed by a reduced benefit in response to a valid cue. It was hypothesised that a reduction in speed of information processing in participants with TBI would lead to reduced benefits and costs (i.e., reduced validity effect) at a short cue-target interval (i.e., 150 $\mathrm{ms}$ ) compared to controls. However, when given more time to process the information (i.e., 550 and $1000 \mathrm{~ms}$ intervals), it was predicted that their orienting pattern would resemble that of controls. Based on the Posner and Petersen (1990) model, it was further hypothesised that under dual task conditions the frontal lobe damage associated with TBI would lead to this group displaying significant deficits of the anterior attention system. As a result, it was predicted that, under the dual task condition, participants with TBI would display a greater decrement in performance than the control group on both the COAT (posterior) and language (anterior) tasks, with the deficit in COAT performance in the group with TBI being the result of the disruption to executive (anterior) attentional functions attributed to frontal lobe damage. According to the Posner model, the language-based task contains more anterior involvement than the COAT task. Thus it was further predicted that, under dual task conditions, there would be a greater decrement in the performance of the group with TBI on the language than the COAT task.

\section{METHOD}

\section{Participants}

Thirty-five individuals with severe non-penetrating TBIs (28 males, 7 females) and 35 controls (20 males, 15 females) took part in this study. Participants with TBI were recruited from consecutive admissions, over a 3-year period, to an outpatient community rehabilitation program. Severity of injury was classified by the lowest recorded Glasgow Coma Scale score (Teasdale \& Jennett, 1974) in the first 24 hours post injury (GCS $<8$ ) and/or a post traumatic amnesia period of $>24$ hours (Julia Farr Post-Traumatic Amnesia Scale; Forrester \& Geffen, 1995). Where JF-PTA scores were not available, retrospective reports were used. Potential participants with a history of major psychiatric disorder, intellectual disability, or other neurological disorders were excluded from the study, as were those who had a hemiplegia of their dominant hand, whose native language was not English, or who had a documented history of substance abuse. Potential participants were also excluded from the study if they displayed symptoms of hemi-neglect, or if they suffered any visual problems (e.g., field loss or diplopia), as assessed by either the rehabilitation or opthalmological medical consultant. The 35 control participants were matched to the sample with TBI on the basis of age, estimated premorbid IQ, and years of education. The National Adult Reading Test Revised (UK) was used to estimate premorbid IQ (Crawford, 1992). Demographic and clinical screening data for both groups are displayed in Table 1.

\section{Tasks}

Covert Orienting of Attention Task

This task was based upon the COAT originally devised by Posner (1980). Participants were seated

Table 1. Means and Standard Deviations for Demographic and Clinical Screening Data for Both Patients With TBI and Control Group Participants.

\begin{tabular}{lcc}
\hline & $\begin{array}{c}\text { Patients with TBI } \\
(n=35)\end{array}$ & $\begin{array}{c}\text { Controls } \\
(n=35)\end{array}$ \\
\hline Age (years) & 28.9 & 30.2 \\
Education (years) & $(11.5)$ & $(10.3)$ \\
& 12.0 & 12.6 \\
Premorbid IQ Estimate & $(1.5)$ & $(2.0)$ \\
& 95.4 & 101.1 \\
Finger Tapping Speed & $(8.6)$ & $(9.1)$ \\
& 42.6 & 50.1 \\
GCS & $(8.9)$ & $(6.8)$ \\
& 5.6 & \\
PTA (days) & $(3.0)$ & \\
& 42.5 & \\
Time Since Injury & $(35.9)$ & \\
(days) & 843.8 & \\
\end{tabular}

Note. TBI $=$ Traumatic Brain Injury GCS $=$ Glasgow Coma Scale; PTA = Post-Traumatic Amnesia. 
at a table in a dimmed room in front of an LED display unit. On the table was located a response button which they were required to press, as quickly as possible, with the index finger of their preferred hand in response to the presentation of one of two possible peripheral target lights on the LED display unit. The target lights were presented at eye level and 9 degrees laterally to the left or right of a central fixation point. A chin rest was mounted on the table to ensure that the participant's nasion remained a constant 1 metre from the point of fixation, thus ensuring that the visual angle was preserved.

The specifications for the LED stimulus display unit were based on the units used by Clark, Geffen, and Geffen (1989), Cremona-Meteyard et al. (1992), Cremona-Meteyard and Geffen (1994), and Wright et al. (1990). The LED unit consisted of a $350 \mathrm{~mm}$ long by $38 \mathrm{~mm}$ wide metal rod set in a horizontal position. The centre of the rod contained 21 symmetrically arranged $3 \mathrm{~mm}$ red LEDs. Both directional and neutral cues were generated by the illumination of the appropriate combination of these LEDs. Single $3 \mathrm{~mm}$ red target LEDs were located $160 \mathrm{~mm}$ to the left and right of the central display.

Visual cues were presented at the central fixation point at three intervals $(150,550$, or $1000 \mathrm{~ms})$ before the onset of the target. The cue remained on during target presentation, and both cue and target were terminated either by participant response, or $900 \mathrm{~ms}$ after target onset. The inter-trial interval was fixed at $1000 \mathrm{~ms}$. Responses $<100$ and $>900 \mathrm{~ms}$ following target onset were assumed to indicate anticipatory responses or lapses of attention and so were excluded. On 18 of the 108 trials presented in each block, a neutral central cue was presented in the form of a plus $(+)$ sign, indicating that the target was equally likely to occur on the left or right. Directional (arrow) cues made up the remaining 90 trials, with arrow cues correctly predicting the target side (valid cue) occurring on 72 of the trials. The remaining 18 directionally cued trials were invalid. In each block, and in each condition (i.e., neutral, valid, and invalid), the number of targets presented to the left and right visual field was equal. Likewise, the three different cue-target intervals were distributed evenly across cue conditions and visual fields. Participant RTs in response to each of the trials were recorded for analysis.

In order to ensure that only the orienting of attention was being measured, independent of eye movement, both horizontal and vertical eye movements were recorded using four $8 \mathrm{~mm}$ silver cup electrodes located on the outer canthi of both eyes, and the upper and lower orbit of the left eye. The EOG amplifier was set to have a gain of 10,000 times and bandpass filter (6db / octave) settings of $0.03 \mathrm{~Hz}$ to $30 \mathrm{~Hz}$ at $-3 \mathrm{db}$. All inter-electrode impedences were maintained below $5 \mathrm{kOhms}$ throughout the study. Trials were not included in data collection if eye movements exceeded the rejection threshold of 100 microvolts.

\section{Phoneme Detection Task}

This task was based upon the phoneme detection task incorporated in the work of Posner et al. (1987). Participants were required to count the number of words beginning with the phoneme 'p' occurring in a designated list of auditorily presented words. Each list contained 20 nouns, with one to seven words beginning with the phoneme 'p'. Only nouns were used. At the end of each list participants were asked how many words from the list began with the sound ' $\mathrm{p}$ '. Thirty word lists were presented using a cassette tape player at the rate of one word every two seconds. All words presented were taken from Kucera and Francis (1967) using the following criteria: maximum frequency $=10,000$, minimum frequency $=10$, maximum word length $=9$ letters, and minimum word length $=4$ letters. The scores obtained represented the number of words beginning with ' $p$ ' in each list that were not detected.

\section{Finger Tapping Test (Spreen \& Strauss, 1991)}

This test was included to control for the effects of deficits in motor speed that may contribute to reduced RTs on the COAT task. Participants were instructed to place the index finger of their preferred hand on a response button and given 5 consecutive attempts to see how many button presses they could achieve within a 10 second period. The procedure was then repeated with the non-preferred hand. The five consecutive trials for each hand must be within a five-point range from fastest to slowest. Where trials fell outside of this range, additional trials were given so that a sample of 5 trials within a 5-point range of each other could be achieved. The mean number of button presses achieved across the five trials for the preferred and non-preferred hands was recorded. The testing apparatus used was an AIM (Cambridge) biosciences laboratory modular unit configured specifically for the current task.

\section{Procedure}

The data were gathered over two separate sessions. Session 1 involved administering the Finger Tapping Test, NART-R, and two practice blocks of 108 trials of the COAT task. Session 2, conducted two to seven days later, included the COAT task, Phoneme Detection Task, and the Dual task (COAT and Phoneme Detection combined). The order of presentation of the COAT and Phoneme Detection tasks was coun- 
terbalanced to allow for effects of order. Five blocks of 108 trials were presented. The dual task (COAT and Phoneme Detection) was then presented following a break of 20 minutes. The total duration of session 2 was approximately 120 minutes.

\section{RESULTS}

All data were analysed using SPSS version 9.0 (SPSS, 1998). Scores on the matching and control variables were analysed first to determine whether there were any significant differences between the two groups. Where significant differences were found, these variables were entered as covariates into the subsequent analyses. The COAT performance of the TBI and control group was then compared using an ANCOVA. A further three ANCOVAs were then performed to examine the specific benefits and costs associated with the different cue types, along with an analysis of the validity effects. Main and interaction effects that were not specifically related to benefit, cost, or validity effects were not reported here as they were dealt with in the previous analyses. Finally, performance on the secondary (phoneme detection) task was analysed in both the single and dual task conditions.

\section{Matching and Control Variables}

While the TBI and control groups were successfully matched for age and years of education (refer to Table 1), there were significant differences between the two groups in terms of premorbid IQ estimate $(F(1,69)=7.15, p=.009)$, finger tapping speed $(F(1,69)=15.64, p=.000)$, and gender, $\left(\chi^{2}(1,60)=6.69\right)$. The contribution of gender to COAT performance has not been reported in previous studies. However, given the imbalance of gender within the group with TBI, it was decided to investigate whether there were any significant gender differences in COAT performance. TBI and control groups were combined for the purposes of this analysis. F-ratios were calculated for all of the COAT conditions but none of these reached significance. As a result, only premorbid IQ estimate and finger tapping speed were entered as covariates into the subsequent analyses.

\section{COAT Task}

The COAT task was analysed using a 4 way repeated measures ANCOVA to examine the effects of Group (TBI vs. Control), Cue Type (valid, neutral, invalid), Cue-Target Interval (150, 550, 1000 $\mathrm{ms}$ ), and Task Type (single vs. dual) on RTs. Estimated premorbid IQ and finger tapping speed

Table 2. COAT (Single Task) Data: Means and Standard Deviations of the Median Reaction Times for Each of the Cue-Target Intervals.

\begin{tabular}{|c|c|c|c|c|c|c|c|}
\hline $\begin{array}{l}\text { Cue- } \\
\text { Target } \\
\text { Interval }\end{array}$ & Group & Valid Cue & $\begin{array}{l}\text { Neutral } \\
\text { Cue }\end{array}$ & $\begin{array}{l}\text { Invalid } \\
\text { Cue }\end{array}$ & $\begin{array}{l}\text { Benefit } \\
\text { (Neutral- } \\
\text { Valid RT) }\end{array}$ & $\begin{array}{l}\text { Cost } \\
\text { (Invaid- } \\
\text { Neutral) }\end{array}$ & $\begin{array}{l}\text { Validity } \\
\text { Effect } \\
\text { (Invalid- } \\
\text { Valid RT) }\end{array}$ \\
\hline $150 \mathrm{~ms}$ & $\begin{array}{l}\text { TBI } \\
\text { Controls }\end{array}$ & $\begin{array}{c}412.8 \\
(77.2) \\
343.7 \\
(57.5)\end{array}$ & $\begin{array}{c}429.8 \\
(80.5) \\
365.1 \\
(55.2)\end{array}$ & $\begin{array}{c}432.0 \\
(80.2) \\
372.9 \\
(63.0)\end{array}$ & $\begin{array}{c}17.0 \\
(21.0) \\
21.4 \\
(14.9)\end{array}$ & $\begin{array}{c}2.2 \\
(24.0) \\
7.9 \\
(18.6)\end{array}$ & $\begin{array}{c}19.2 \\
(19.2) \\
29.2 \\
(25.2)\end{array}$ \\
\hline $550 \mathrm{~ms}$ & $\begin{array}{l}\text { TBI } \\
\text { Controls }\end{array}$ & $\begin{array}{l}341.0 \\
(66.5) \\
285.1 \\
(38.3)\end{array}$ & $\begin{array}{c}354.1 \\
(65.9) \\
302.8 \\
(40.7)\end{array}$ & $\begin{array}{c}388.6 \\
(77.5) \\
331.1 \\
(50.6)\end{array}$ & $\begin{array}{c}13.1 \\
(28.8) \\
17.7 \\
(22.6)\end{array}$ & $\begin{array}{c}34.5 \\
(42.0) \\
28.3 \\
(28.7)\end{array}$ & $\begin{array}{c}47.6 \\
(37.9) \\
46.0 \\
(33.5)\end{array}$ \\
\hline $1000 \mathrm{~ms}$ & $\begin{array}{l}\text { TBI } \\
\text { Controls }\end{array}$ & $\begin{array}{l}316.9 \\
(68.0) \\
262.4 \\
(31.9)\end{array}$ & $\begin{array}{l}326.0 \\
(69.3) \\
276.8 \\
(38.1)\end{array}$ & $\begin{array}{l}360.4 \\
(90.4) \\
301.9 \\
(47.2)\end{array}$ & $\begin{array}{c}9.1 \\
(22.3) \\
14.4 \\
(17.8)\end{array}$ & $\begin{array}{c}34.4 \\
(51.3) \\
25.1 \\
(27.1)\end{array}$ & $\begin{array}{c}43.4 \\
(51.3) \\
39.5 \\
(32.3)\end{array}$ \\
\hline
\end{tabular}

Note. COAT $=$ Covert Orienting of Attention Task; RT $=$ Reaction Time; TBI $=$ Traumatic Brain Injury. 
Table 3. COAT (Dual Task) Data: Means and Standard Deviations of the Median Reaction Times for Each of the Cue-Target Intervals.

\begin{tabular}{|c|c|c|c|c|c|c|c|}
\hline $\begin{array}{l}\text { Cue-Target } \\
\text { Interval }\end{array}$ & Group & Valid Cue & $\begin{array}{l}\text { Neutral } \\
\text { Cue }\end{array}$ & $\begin{array}{l}\text { Invalid } \\
\text { Cue }\end{array}$ & $\begin{array}{l}\text { Benefit } \\
\text { (Neutral- } \\
\text { Valid RT) }\end{array}$ & $\begin{array}{l}\text { Cost } \\
\text { (Invaid- } \\
\text { Neutral) }\end{array}$ & $\begin{array}{l}\text { Validity } \\
\text { Effect } \\
\text { (Invalid- } \\
\text { Valid RT) }\end{array}$ \\
\hline \multirow[t]{2}{*}{$150 \mathrm{~ms}$} & TBI & $\begin{array}{c}413.1 \\
(66.6)\end{array}$ & $\begin{array}{c}440.4 \\
(72.4)\end{array}$ & $\begin{array}{c}445.4 \\
(83.1)\end{array}$ & $\begin{array}{c}27.2 \\
(28.7)\end{array}$ & $\begin{array}{c}5.1 \\
(50.5)\end{array}$ & $\begin{array}{c}32.3 \\
(36.1)\end{array}$ \\
\hline & Controls & $\begin{array}{l}351.4 \\
(52.8)\end{array}$ & $\begin{array}{l}366.6 \\
(53.6)\end{array}$ & $\begin{array}{l}377.6 \\
(58.0)\end{array}$ & $\begin{array}{c}15.2 \\
(15.8)\end{array}$ & $\begin{array}{c}11.0 \\
(22.7)\end{array}$ & $\begin{array}{c}26.2 \\
(20.1)\end{array}$ \\
\hline \multirow[t]{2}{*}{$550 \mathrm{~ms}$} & TBI & $\begin{array}{c}349.3 \\
(61.1)\end{array}$ & $\begin{array}{c}372.6 \\
(70.7)\end{array}$ & $\begin{array}{c}397.1 \\
(81.3)\end{array}$ & $\begin{array}{c}23.3 \\
(28.1)\end{array}$ & $\begin{array}{l}24.6 \\
(50.51)\end{array}$ & $\begin{array}{c}47.9 \\
(43.7)\end{array}$ \\
\hline & Controls & $\begin{array}{c}294.4 \\
(40.3)\end{array}$ & $\begin{array}{c}316.1 \\
(47.6)\end{array}$ & $\begin{array}{l}344.6 \\
(44.0)\end{array}$ & $\begin{array}{c}21.8 \\
(21.3)\end{array}$ & $\begin{array}{c}28.4 \\
(23.9)\end{array}$ & $\begin{array}{c}50.2 \\
(27.7)\end{array}$ \\
\hline \multirow[t]{2}{*}{$1000 \mathrm{~ms}$} & TBI & $\begin{array}{l}320.1 \\
(59.6)\end{array}$ & $\begin{array}{l}335.0 \\
(66.0)\end{array}$ & $\begin{array}{l}367.6 \\
(71.4)\end{array}$ & $\begin{array}{c}14.9 \\
(29.2)\end{array}$ & $\begin{array}{c}32.6 \\
(35.1)\end{array}$ & $\begin{array}{c}47.5 \\
(34.2)\end{array}$ \\
\hline & Controls & $\begin{array}{l}269.4 \\
(39.3)\end{array}$ & $\begin{array}{l}289.4 \\
(46.0)\end{array}$ & $\begin{array}{l}321.9 \\
(51.6)\end{array}$ & $\begin{array}{c}19.9 \\
(19.7)\end{array}$ & $\begin{array}{c}32.6 \\
(28.2)\end{array}$ & $\begin{array}{l}52.5 \\
(29.1)\end{array}$ \\
\hline
\end{tabular}

Note . COAT $=$ Covert Orienting of Attention Task $\mathrm{RT}=$ Reaction Time; $\mathrm{TBI}=$ Traumatic Brain Injury.

were entered as covariates. Reaction times for all single task conditions are reported in Table 2, while reaction times for dual task conditions are reported in Table 3.

The repeated measures ANCOVA revealed significant main effects for Group $(F(1,66)=5.98$, $p=.017)$, Cue Type $(F(2,132)=15.49, \quad p=$ $.000)$, and Cue-Target Interval $(F(2,132)=$ $22.03, p=.000$ ). Overall mean RTs revealed that participants with TBI were approximately 45-70 ms slower than control participants (refer to Tables 2 and 3). With respect to the Cue Type main effect, participants responded fastest to the valid cues and slowest to the invalid cues, with responses to neutral cues being intermediary to the other two cue types. This pattern of RT in response to the varying cue types is clearly illustrated in Figure 1. The main effect of Cue-Target Interval is also illustrated in Figure 1; as cuetarget intervals increased, overall RTs decreased. Contrary to our predictions, there was neither a significant overall effect for Task Type $(F(1,132)=2.0, p=.162)$, or a Task Type by Group interaction $(F(1,66)=.04, \quad p=.847)$, indicating that the introduction of the secondary (language) task had no impact upon COAT task performance, nor were participants with TBI differentially affected by the introduction of the secondary task.

The absence of a Cue Type by Group interaction suggests that, even though the group with TBI was slower, both groups oriented their attention to the three cues in a similar fashion. Again, Figure 1 displays this similar pattern of facilitation and inhibition for both the group with TBI and the control group in response to the three cue types. In addition, and contrary to our hypothesis, when cue-target intervals were increased, participants with TBI displayed the same level of improvement in RT as controls.

\section{Benefit}

To investigate benefits in response to the valid cue (compared to the neutral cue), a Group (TBI vs. controls) by Benefit (Valid RT, Neutral RT) by Cue-Target Interval $(150 \mathrm{~ms}, 550 \mathrm{~ms}, 1000 \mathrm{~ms})$ by Task Type (single vs. dual) repeated measures ANCOVA was performed, with estimated premorbid IQ and finger tapping speed entered as covariates. There was a significant main effect of Benefit $(F(1,66)=6.94, p=.011)$, indicating that participants were able to benefit from the valid cue. However, there was no Group by Benefit interaction, suggesting that both groups 


\section{(a) Group with TBI}

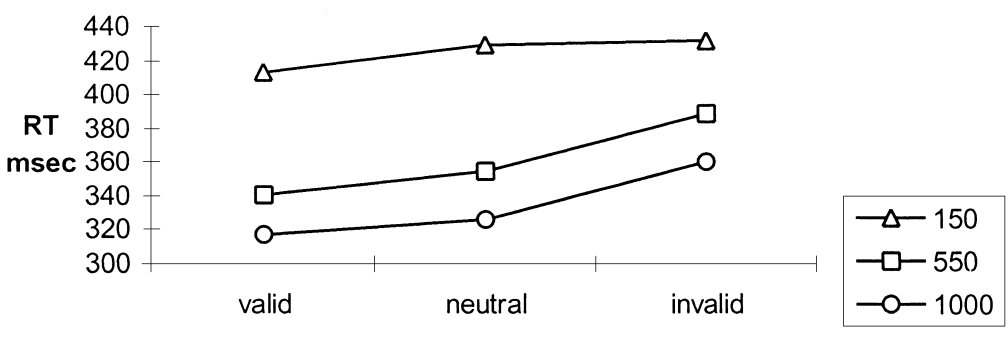

Cue Type

(b) Control Group

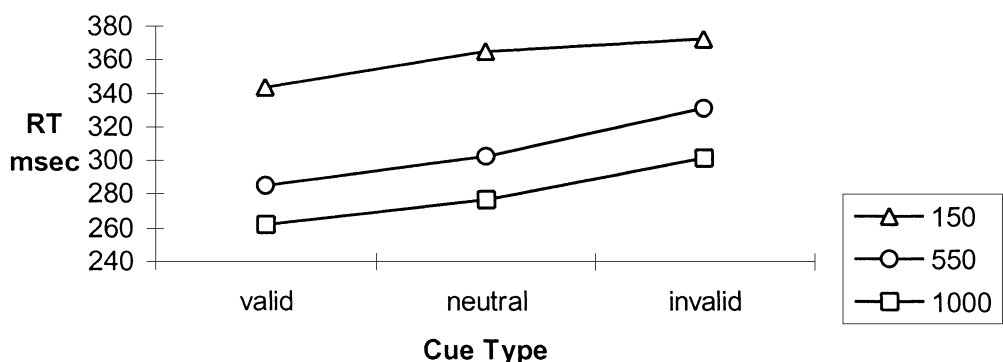

Fig. 1. Mean of median reaction times for (a) TBI and (b) Control participants under single task conditions, and in response to each of the three cue-target intervals $(150,550,1000 \mathrm{~ms})$. (a) Group with TBI. (b) Control Group

benefited equally from the presentation of a valid cue.

\section{Cost}

The cost of an invalid cue (compared to a neutral cue) was analysed using a Group by Cost (neutral RT, invalid RT) by Cue-Target Interval $(150 \mathrm{~ms}$, $550 \mathrm{~ms}, 1000 \mathrm{~ms}$ ) by Task-Type (single vs. dual) repeated measures ANCOVA, using estimated premorbid IQ and finger tapping speed as covariates. A significant main effect for Cost $(F(1,66)=$ $12.70, p=.001$ ) was found, indicating that, overall, participants displayed a cost in RTs to an invalid cue when compared to neutral cue RTs. The absence of a Cost by Group interaction suggests that there were no differences in the costs associated with an invalid cue for the group with TBI and the control group.

\section{Validity Effect}

Jonides and Mack (1984) have questioned the utility of using cost-benefit analysis in relation to neutral cues. These concerns relate to the assumption that, for cost-benefit analysis to be meaningful, "... neutral and informative cueing conditions must be identical with respect to all processing consequences of the cue except the specific preparatory effect elicited by the informative cue" (p. 33). While it was felt that, within the constraints of the task design, the neutral cue in the current study went as close as possible to meeting this criteria, it was nevertheless decided to carry out a separate analysis comparing only the valid and invalid cues (i.e., validity effect). In addition, specific analysis of the validity effect would enable a more detailed inspection of the impact of differing cue-target intervals, for the 
two groups. An examination of Table 2 suggests that, at a cue-target interval of $150 \mathrm{~ms}$, the TBI group's validity effect was substantially less than the control group. However, with the advantage of extra processing time, the TBI group's performance improved markedly to the extent that there was no such difference between the groups at the 550 and $1000 \mathrm{~ms}$ cue-target intervals. A Group (TBI vs. controls) by Validity (valid RT, invalid RT) by Cue-Target Interval $(150 \mathrm{~ms}, 550 \mathrm{~ms}$, $1000 \mathrm{~ms}$ ) by Task Type (single vs. dual) repeated measures ANCOVA (with estimated premorbid IQ and finger tapping speed as covariates) found a significant main effect for Validity $(F(1,66)=$ $20.25, p=.000)$. This significant main effect for Validity indicates that participants were orienting their attention in response to valid and invalid cues. There was no significant interaction between Validity effect and Group, again suggesting that participants with TBI oriented their attention in much the same way as controls, albeit more slowly (i.e., refer to the significant group effect discussed previously). Contrary to our prediction, the absence of a Validity by Group by Cue-Target Interval interaction suggests that, at a cue-target interval of $150 \mathrm{~ms}$, there were no significant differences in validity effects between the two groups.

\section{Secondary Task (Phoneme Detection) Performance}

The mean number of errors made under both single and dual task conditions are reported in Table 4. A Group (TBI vs. Controls) by Task Type (Single, Dual) repeated measures ANCOVA (with estimated premorbid IQ as a covariate) revealed a significant main effect for Group $(F(1,67)=15.17, p=.000)$, showing that participants with TBI produced significantly more errors overall than controls. A significant Group by Task Type interaction $(F(1,68)=11.18$, $p=.001)$ indicates that the group with TBI had a greater increase in error rate under dual task conditions. A subsequent Group (TBI vs. Controls) by Task Type (Single, Dual) ANCOVA (with estimated premorbid IQ as a covariate) revealed that there were no differences between the two groups on the phoneme detection task under single task conditions. However, the intro-
Table 4. Mean (and SD) number of errors for both single and dual task conditions. Single block score represents mean number of errors across 6 lists of 20 words; dual task score represents the mean number of errors across 30 lists of 20 words.

\begin{tabular}{lcc}
\hline Group & Single Task & Dual Task \\
\hline TBI & 0.49 & 2.60 \\
$(n=35)$ & $(0.87)$ & $(2.09)$ \\
Control & & \\
$(n=35)$ & 0.20 & 0.97 \\
& $(0.47)$ & $(0.75)$ \\
\hline
\end{tabular}

Note TBI $=$ Traumatic Brain Injury.

duction of the COAT task resulted in the group with TBI making significantly more errors on the phoneme detection task than controls.

\section{DISCUSSION}

The results of this study indicated that experimental participants with TBI produced significantly slower overall RTs, compared to controls, on the COAT task. However, an analysis of the costs and benefits, in response to the valid, neutral, and invalid cues, found no differences between the two groups. In terms of the Posner model, this would suggest that, despite being slower, participants with TBI oriented their visual attention in much the same way as controls, and displayed the same ability to disengage, move, and engage their attention. As there were no differences between the two groups in terms of their orienting of attention, and as the influence of motor speed was controlled for, it is suggested that the elevated RTs of the group with TBI represent a deficit in the speed of information processing in this group.

The finding of a normal orienting pattern in participants with TBI was not consistent with the work of Cremona-Meteyard and colleagues who found deficits in the 'pre-aligning' (engaging) of attention in participants with mild, moderate, and severe TBI (Cremona-Meteyard et al., 1992; Cremona-Meteyard \& Geffen, 1994). However the findings of the current study replicated the 
findings of Pavese et al. (submitted for publication) and Sandson et al. (1988) who reported that participants with TBI were able to orient their attention in the same way as controls. When comparing the Cremona-Meteyard study with the current study, there are a number of factors that may have contributed to the discrepant findings. Firstly, while the mean benefit of the 11 participants with TBI in the Cremona-Meteyard study was only one $\mathrm{ms}$, four of the individuals displayed a benefit in excess of nine ms (the mean benefit of the participants with TBI, at a comparable cue-target interval, in the current study). It is therefore possible that their findings were an artifact of relatively low participant numbers. It is also possible that the failure to find a benefit may have resulted from an artificially low RT to the neutral cue: The neutral cue may not have been as 'neutral' as intended. Difficulties associated with the interpretation of the neutral cue have been raised by Jonides and Mack (1984) who recommend that, if at all possible, neutral cues should be avoided. If the neutral cue is removed from the analysis of the Cremona-Meteyard data, and the validity effect is examined (i.e., RTinvalid-RTvalid), their group with TBI displayed a validity effect of $61 \mathrm{~ms}$ and the control group 73 $\mathrm{ms}$. The validity effect of the group with TBI is clearly indicative of a robust orienting of attention, and is of a similar magnitude to the control group. Of particular interest, is that this validity effect is consistent with the one reported by Pavese et al. (submitted for publication) for their participants with TBI (54 ms), and is greater than the $43 \mathrm{~ms}$ reported in the current study.

The introduction of the secondary (phoneme detection) task had no significant impact upon RTs on the COAT task for either group. This finding is at odds with the work of Posner and Raichle (1994) reported previously, who suggested that the increased load placed on the anterior attention system, particularly the anterior cingulate, was responsible for the decline in COAT performance under dual task conditions. However, Posner and Raichle (1994) also noted that there is a reduction in activation of the anterior cingulate as tasks become more automated. Given that the participants in the current study received two practice blocks of 108 trials, and five blocks of 108 trials under the single task conditions, it seems possible that their COAT task performance may have become quite automated, and therefore required less input from the anterior system, when they commenced the dual task condition. This notion is consistent with anecdotal accounts of participants who reported greater levels of automaticity as the task proceeded. In fact, a number of participants (both controls and those with TBI) indicated that the dual task situation helped them to stay 'on task' with regard to COAT performance. In relation to the Phoneme Detection Task, however, both groups produced low and equivalent error rates under single task conditions but participants with TBI displayed significantly more errors than controls under dual task conditions. The finding of a deficit in attending to auditorily presented language-based information in dual task situations in participants with TBI is an important one. Clinicians working with patients with TBI often report instances of these patients being unable to deal with a motor task while attending to spoken instructions or conversation. Such a finding highlights the need to include dual task conditions and, in particular, an auditory verbal task, when assessing attention in persons who have sustained a TBI.

Of particular interest with the dual task paradigm was that we were able to examine the interaction of tasks considered to be the domain of the posterior (visual orienting) and anterior attention systems (phoneme detection). While the introduction of the dual task had no significant impact upon the RTs of either group on the COAT task, the group with TBI experienced a significant decrement in performance on the phoneme detection task, under dual task conditions. Given the frontal lobe pathology of TBI, the extra demands placed upon the executive component of this frontal system under dual task conditions, resulted in a reduced performance in other functions (i.e., language) performed by the system. The introduction of the secondary language task assisted in the identification of deficits in performance on anterior attention system tasks, in the presence of a preserved posterior attention system, in persons with TBI. This finding is entirely consistent with the current literature that has examined the roles of the anterior and posterior 
attention systems underlying these tasks (Posner et al., 1989), and the known pathophysiology of TBI (Blumbergs, 1997).

While the findings of the current study were in line with the model of attention proposed by Posner and Petersen (1990), there are a number of methodological issues that warrant consideration. First, it is not possible to determine whether the deficits displayed by participants with TBI in attending to auditory-verbal information under dual task conditions were the result of discrete attentional processes or deficits in other areas, such as a generalized slowing of information processing, reduced attentional capacity, or impaired memory function. A further limitation of the secondary task relates to the method by which participants remembered and monitored the number of words within each list. While some participants used solely 'mental operations', others used their fingers to 'record' each target word as it was presented. It is possible that the superior performance of the control group can be accounted for by the use of more efficient strategies during the dual task condition rather than any specific attentional processes. The presentation of more prescriptive instructions for the phoneme detection task would help to reduce this problem. Finally, there are limits to the extent to which it is possible to delineate the specific mental operations (i.e., disengage, move, engage) invoked by the valid, neutral, and invalid cues. CremonaMeteyard et al. (1992) highlighted the difficulties associated with comparing pre- and post-target operations. For example, the disengaging of attention to move towards an anticipated target location would appear to be a different process to the disengaging of attention and moving towards a confirmed target location (i.e., after a target appears at a non-cued location). Perhaps in recognition of some of these difficulties, Posner's more recent work (e.g., Pavese et al., submitted for publication) appears to have focused upon the overall orienting processes rather than its individual components. Despite these issues, the COAT task still remains a valuable theoretically based tool for investigating the orienting of visual attention.

In conclusion, participants with TBI displayed a robust orienting of attention on the COAT task under both single and dual task conditions, reflecting an intact posterior attention system. However, the introduction of the dual task condition, produced a significant reduction in the performance of participants with TBI on the auditory-language task (phoneme detection). Such a finding is entirely consistent with the known pathophysiology of TBI and the model of attention proposed by Posner and Petersen (1990): Under dual task conditions, participants with TBI display features of a compromised anterior attention system, while the posterior attention system appears to be intact. The finding of 'attentional' deficits on the language task under the dual, compared to the single, task condition is particularly important. Such a finding confirms the claim of Robertson (1995) that dual task conditions are able to 'unmask' attentional deficits that would otherwise go undetected under single task conditions. As a result, the inclusion of dual task conditions is critical to the clinical assessment of individuals with TBI.

\section{REFERENCES}

Blumbergs, P.C. (1997). Pathology. In P. Reilly \& R. Bullock (Eds.), Head injury. London: Chapman \& Hall.

Clark, C.R., Geffen, G.M., \& Geffen, L.B. (1989). Catecholamines and the covert orientation of attention in humans. Neuropsychologia, 27, 131-139.

Crawford, J.R. (1992). Current and premorbid intelligence measures in neuropsychological assessment. In J.R. Crawford, D.M. Parker, \& W.W. McKinlay (Eds.), A handbook of neuropsychological assessment. Hove: Lawrence Erlbaum.

Cremona-Meteyard, S.L., Clark, C.R., Wright, M.J., \& Geffen, G.M. (1992). Covert orientation of visual attention after closed head injury. Neuropsychologia, 30(2), 123-132.

Cremona-Meteyard, S.L., \& Geffen, G.M. (1994). Persistent visuospatial attention deficits following mild head injury in Australian rules football players. Neuropsychologia, 32(6), 649-662.

Forrester, G., \& Geffen, G.M. (1995). Julia Farr Services Post-Traumatic Amnesia Scales Manual. Adelaide: Julia Farr Foundation.

Godefroy, O., Lhullier, C., \& Rousseaux, M. (1996). Non-spatial attention disorders in patients with frontal or posterior brain damage. Brain, 119, 191-202.

Gronwall, D. (1987). Advances in the assessment of attention and information processing after head 
injury. In H.A. Levin, J. Grafman, \& H.N. Eisenberg (Eds.), Neurobehavioural recovery from head injury (pp. 354-371). New York: Oxford University Press.

Hartman, A., Pickering, R.M., \& Wilson, B.A. (1992). Is there a central executive deficit after severe head injury? Clinical Rehabilitation, 6, 133-140.

Jonides, J., \& Mack, R. (1984). On the cost and benefit of cost and benefit. Psychological Bulletin, 96, 2944.

Kucera, H., \& Francis, W.N. (1967). Computational analysis of present-day American English. Providence, RI: Brown University Press.

Lezak, M.D. (1995). Neuropsychological assessment. New York: Oxford University Press.

Loken, W.J., Thornton, A.E., Otto, R.L., \& Long, C.J. (1995). Sustained attention after severe closed head injury. Neuropsychology, 9, 592-598.

McKinlay, W.W., Brooks, D.N., Bond, M.R., Martinage, D.P., \& Marshall, M.M. (1981). The shortterm outcome of severe blunt head injury as reported by relatives of the injured persons. Journal of Neurology, Neurosurgery, and Psychiatry, 44, 527533.

Pavese, A., Heidrich, A., Sohlberg, M.M., Laughlin, K.A., \& Posner, M.I. (2000). Pathologies of attentional networks following traumatic brain injury. Manuscript submitted for publication.

Petersen, S.E., Fox, P.T., Posner, M.I., Mintun, M., \& Raichle, M.E. (1988). Positron emission tomographic studies of the cortical anatomy of single word processing. Nature, 331, 585-589.

Ponsford, J., \& Kinsella, G. (1992). Attentional deficits following closed head injury. Journal of Clinical and Experimental Neuropsychology, 14, 822-838.

Ponsford, J.L., Olver, J.H., \& Curran, C. (1995). A profile of outcome: 2 years after traumatic brain injury. Brain Injury, 9, 1-10.

Posner, M.I. (1980). Orienting of attention. Quarterly Journal of Experimental Psychology, 41A, 19-45.

Posner, M.I., Cohen, Y., \& Rafal, R.D. (1982). Neural systems control of spatial orienting. Philosophical Transactions of the Royal Society of London. Series B: Biological Sciences, 298, 187-198.

Posner, M.I., Walker, J.A., Friedrich, F.J., \& Rafal, R.D. (1984). Effects of parietal injury on covert orienting of attention. The Journal of Neuroscience, 4, 18631874.

Posner, M.I., Inhoff, A.W., Friedrich, F.J., \& Cohen, A. (1987). Isolating attentional systems: A cognitiveanatomical analysis. Psychobiology, 15, 107-121.

Posner, M.I., Petersen, S.E., Fox, P.T., \& Raichle, M.E. (1988). Localization of cognitive operations in the human brain. Science, 240, 1627-1631.

Posner, M.I., Sandson, J., Dhawan, M., \& Shulman, G.L. (1989). Is word recognition automatic? A cognitive-anatomical approach. Journal of Cognitive Neuroscience, 1(1), 50-60.
Posner, M.I., \& Petersen, S.E. (1990). The attention system of the human brain. Annual Review of Neuroscience, 13, 25-42.

Posner, M.I., \& Raichle, M.E. (1994). Images of mind. New York: Scientific American Library.

Robertson, I.H. (1995). Neuropsychological rehabilitation, attention and unilateral neglect. Paper presented at the International Neuropsychological Society / Australian Society for the Study of Brain Impairment annual conference, Cairns, Australia.

Roland, P.E. (1985). Cortical organisation of voluntary behaviour in man. Human Neurobiology, 4, 155167.

Sandson, J., Crosson, B., Posner, M.I., Barco, P.P., Velozo, C.A., \& Brobeck, T.C. (1988). Attentional imbalances following head injury. In J.M. Williams \& C.J. Long (Eds.), Cognitive approaches to neuropsychology. New York: Plenum.

Schmitter-Edgecombe, M. (1996). Effects of divided attention on implicit and explicit memory performance following severe closed head injury. Neuropsychology, 10, 155-167.

Schmitter-Edgecombe, M., \& Kibby, M.K. (1998). Visual selective attention after severe closed head injury. Journal of the International Neuropsychological Society, 4, 144-159.

Spreen, O., \& Strauss, E. (1991). A compendium of neuropsychological tests: Administration, norms, and commentary. New York: Oxford University Press.

SPSS for Windows, Release 9.0 [Computer software]. (1998). Chicago: SPSS Inc.

Stuss, D.T., Stethem, H., Hugenholtz, H., \& Richard, M.T. (1989). Traumatic brain injury: A comparison of three clinical tests, and analysis of recovery. The Clinical Neuropsychologist, 3, 145-156.

Stuss, D.T., Pogue, J., Buckle, L., \& Bondar, J. (1994). Characterization of stability of performance in patients with traumatic brain injury: Variability and consistency on reaction time tests. Neuropsychology, 8, 316-324.

Swanson, J.M., Posner, M., Potkin, S., Bonforte, S., Youpa, D., Fiore, C., Cantwell, D., \& Crinella, F. (1991). Activating tasks for the study of visualspatial attention in ADHD children: A cognitive anatomical approach. Journal of Child Neurology, 6(Supplement), s119-s127.

Teasdale, G., \& Jennett, B. (1974). Assessment of coma and impaired consciousness. Lancet, 81-84.

van Zomeren, A.H. (1981). Reaction time and attention after closed head injury. Lisse: Swets \& Zeitlinger B.V.

van Zomeren, A.H., \& Brouwer, W.H. (1987). Head injury and concepts of attention. In H. S. Levin, J. Grafman, \& H. Eisenberg (Eds.), Neurobehavioral recovery from head injury. New York: Oxford.

Whyte, J., Polansky, M., Fleming, M., Coslett, H.B., \& Cavallucci, C. (1995). Sustained arousal and atten- 
tion after traumatic brain injury. Neuropsychologia, 33, 797-813.

Wright, M.J., Burns, R.J., Geffen, G.M., \& Geffen, L.B. (1990). Covert orientation of visual attention in parkinson's disease: An impairment in the maintenance of attention. Neuropsychologia, 28, 151-159.
Wright, M.J., Cremona-Meteyard, S.L., Geffen, L.B., \& Geffen, G.M. (1994). The effects of closed head injury, senile dementia of the alzheimer's type, and parkinson's disease on covert orientation of visual attention. Australian Journal of Psychology, 46, 6372. 